\title{
Australian chiropractors' perception of the clinical relevance of anatomical sciences and adequacy of teaching in chiropractic curricula
}

\author{
Rosemary Giuriato ${ }^{1,2^{*}}$, Goran Štrkalj ${ }^{1}$, Tania Prvan $^{3}$ and Nalini Pather ${ }^{1}$
}

\begin{abstract}
Background: Human anatomy education is compulsory in the undergraduate curriculum in all Australian chiropractic education programs. There is very little data on clinicians' perceptions of the adequacy of their anatomy training and its relevance to practice. The aims of this study were to evaluate Australian registered chiropractors' perceptions on the relevance and adequacy of anatomy training for clinical practice and analyse their opinion on the usefulness of the teaching resources utilized during their preprofessional training.

Methods: A questionnaire-based survey was conducted on a sample of Australian registered chiropractors focussing on the adequacy of their anatomical science (gross anatomy, histology, neuroanatomy and embryology) training and the clinical relevance of each individual sub-discipline, and the perceived value of each of the different anatomy teaching resources utilized.

Results: A total of 128 completed surveys were returned from an estimated 387 attendees at two national chiropractic conferences (estimated 33\% response rate). The respondents represent $2.6 \%$ of registered chiropractors in Australia in 2016 and were representative in terms of gender (66.4\% male) but not age, with older generations being overrepresented (peak age group 35-44 vs. 25-34). The majority of the survey respondents obtained their chiropractic qualification in Australia (89.1\%) and graduated after 1990 with an average of 21.7 years (SD $=11.3$, range $=1-44)$ in practice. Respondents were equally likely to have undertaken anatomy training in Medicine, Science, Health Science, or other faculties. The disciplines perceived most relevant for clinical practice were neuroanatomy (100\% of respondents agreeing) and gross anatomy (99.2\%), followed by histology (86.0\%) and embryology (81.1\%). Respondents also perceived their training to be most adequate in neuroanatomy (99.3\%) and gross anatomy (99.2\%) followed by histology (91.4\%) and embryology (85\%). Respondents confirmed exposure to a varied suite of anatomy teaching tools utilized during their pre-professional training and highly valued access to cadavers and prosected specimens.

Conclusions: The majority of respondents perceived anatomy as highly relevant to their clinical practice and noted that it was adequately taught within a wide range of educational approaches. These results will assist educators to refine content and delivery of anatomy course offerings to maximize relevance in chiropractic clinical practice.
\end{abstract}

Keywords: Anatomy, Chiropractic, Education

\footnotetext{
* Correspondence: rosemary.giuriato@mq.edu.au

'Department of Anatomy, School of Medical Sciences, Faculty of Medicine,

The University of New South Wales, Sydney, New South Wales, Australia

${ }^{2}$ Department of Chiropractic, Faculty of Science and Engineering, Macquarie

University, Macquarie Park, Australia

Full list of author information is available at the end of the article
}

\section{$\triangle B M C$}

(c) The Author(s). 2020 Open Access This article is licensed under a Creative Commons Attribution 4.0 International License, which permits use, sharing, adaptation, distribution and reproduction in any medium or format, as long as you give appropriate credit to the original author(s) and the source, provide a link to the Creative Commons licence, and indicate if changes were made. The images or other third party material in this article are included in the article's Creative Commons licence, unless indicated otherwise in a credit line to the material. If material is not included in the article's Creative Commons licence and your intended use is not permitted by statutory regulation or exceeds the permitted use, you will need to obtain permission directly from the copyright holder. To view a copy of this licence, visit http://creativecommons.org/licenses/by/4.0/ The Creative Commons Public Domain Dedication waiver (http://creativecommons.org/publicdomain/zero/1.0/) applies to the data made available in this article, unless otherwise stated in a credit line to the data. 


\section{Background}

Chiropractors are allied health professionals with a focus on "the diagnosis, treatment and prevention of mechanical disorders of the musculoskeletal system" [1]. Chiropractors apply a range of manual therapeutic techniques directed to the patient's spine and extremities with the aim to restore joint function, reduce pain and encourage mobility [2]. Given that musculoskeletal conditions are highly prevalent [3] and that approximately one in three Australians seek chiropractic care in a 12 month period [4], it is important to ascertain whether Australian chiropractors perceive their training in anatomy adequate to provide competent diagnoses and management of musculoskeletal conditions. As primary healthcare providers, patients are able to access chiropractic services without the need of a health practitioner's referral. Sound anatomical knowledge is essential for the safe delivery of manipulative techniques required as a part of chiropractic clinical practice [5].

In Australia, evidence-based chiropractic education offered in public universities can be traced back to 1990 when the Sydney College of Chiropractic merged with Macquarie University in Sydney, to provide the first chiropractic program at a government funded public university in the world [6,7]. Registration to practice chiropractic requires the completion of an undergraduate and/or postgraduate degree from one of four accredited programs in Australia [8]. Regulation of chiropractic education in Australia has been the responsibility of the Council on Chiropractic Education Australasia (CCEA) since 2010, when the profession was included in the National Registration and Accreditation Scheme. The CCEA formulates and oversees the accreditation standards applicable to chiropractic programs [9]. Previously published educational standards for the first professional chiropractic award programs (2009-2017) [10] identified the need to incorporate biomedical sciences in the chiropractic program curriculum. These biomedical sciences included "anatomy, biochemistry, physiology, neurology, microbiology, histology, embryology, pathology, biophysics, molecular and cell biology, genetics, immunology, and other appropriate subjects" [10]. These standards did not prescribe core content but rather made the recommendation that the biomedical sciences were to "ensure an in-depth understanding of basic biological principles, consisting of a core of information on the fundamental structures, functions and interrelationships of the body systems" leading to the "understanding of the scientific knowledge, concepts and methods fundamental to acquiring and applying clinical science" [10].

Currently, all four chiropractic programs delivered in Australia include human anatomy courses as a compulsory requirement in their undergraduate curriculums $[8,11]$. Australian chiropractic programs follow a sequential training program, progressing the student from the foundational biomedical sciences in the undergraduate years to full clinical internship or work integrated units at the end of their academic programs.

Relevance of education to clinical practice is one of the most important aspects of teaching and learning [12]. To date, there exists little information on chiropractors' perceived relevance and adequacy of their anatomy education to their clinical practice. Previous research exploring pre-professional anatomy education within chiropractic programs confirmed considerable investment in anatomy teaching resources [8, 11, 13] but provided little insight into chiropractors' perceptions of the usefulness of these teaching tools. Determining chiropractors' perceptions of these tools will assist to develop anatomy curricula appropriate for chiropractic clinical practice. Clinicians are uniquely able to offer input on anatomical sciences education as they are at the forefront of both the theoretical application of knowledge to clinical practice and of changes to the practice of the profession $[14,15]$.

Analysis of chiropractors' opinion on the application of knowledge adopted during their education to clinical practice is imperative for investigating the relevance and adequacy of their education and informs educators on possible changes that may be considered in future course offerings. It also provides an opportunity to reflect on adequacy of curriculum content and usefulness for clinical application.

\section{Aims}

The aims of this study were to evaluate Australian registered chiropractors' perceptions of the relevance and adequacy of anatomy training for clinical practice and determine their opinion on the usefulness of the teaching resources utilized during their anatomy training.

\section{Methods}

This study used a questionnaire-based survey tool modified from similar previously published surveys which evaluated the relevance of gross human anatomy in clinical medical practice $[16,17]$ and the methods used to study anatomy [18]. The survey was modified to suit chiropractic clinicians and refined in consultation with four academic experts in anatomy and four chiropractic clinicians, prior to distribution.

The questionnaire collected demographic data (gender, age), year of graduation, years in clinical practice, country in which degree was completed, institution conferring qualification (for extrapolation of country data), home faculty delivering anatomy content, qualifications of anatomy staff and the usefulness of the anatomy teaching resources used during their training. The questionnaire also posed questions regarding the relevance of anatomy, adequacy of anatomical training, rated on a 6- 
point Likert scale (strongly disagree, disagree, somewhat disagree, somewhat agree, agree, strongly agree), and value of various education resources, rated on a 7-point Likert-type scale (extremely helpful, quite helpful, moderately helpful, slightly helpful, not at all helpful, not sure, or was not used) [19].

The surveys were anonymously completed. Printed copies of the survey were distributed at the start of the two Australian chiropractic association's national conferences held in Sydney in late 2016 (Chiropractic Australia) and in Canberra in early 2017 (Australian Chiropractors Association). Ethical approval was obtained from the Human Research Ethics Committee of UNSW, Sydney (HC17058).

\section{Data analysis}

Descriptive statistics were used to compare respondents' age and gender distribution to registered chiropractors in Australia (2016) and to test the homogeneity in the distribution of country where qualification was obtained (Australia, elsewhere), year of chiropractic qualification (<1978 1981-1990, > 1990), and anatomy home-faculty (Medicine, Science, Health Science, other). Cut points for year of chiropractic qualification were selected based on key periods for the Chiropractic profession in Australian history (1978: registration of chiropractic as a profession; 1990: first public university-based education program). The age of respondents was grouped in 10year intervals $(<25,25-34,35-44,45-54,55-64,>65$ years) and the distribution compared against the population of Australian registered chiropractors in 2016 [20].

The Chi-squared test was used to test the homogeneity in distribution of responses for adequacy in training and clinical relevance for each of the sub-disciplines (gross anatomy, histology, neuroanatomy, embryology). Response categories were collapsed [21] and grouped by negative responses (strongly disagree, disagree, somewhat disagree), or positive responses (somewhat agree, agree, strongly agree). Statistical analysis was completed using SPSS Statistics for Windows, version 23.0.0.0 (IBM Corp., Armonk, NY).

\section{Results}

\section{Study population}

Based on conference registrations, it is estimated that 387 chiropractors attended one or both of the two professional associations' national conferences, of which 128 (33\%) attendees completed the survey. Attendees were requested to only complete the survey once. This represented $2.6 \%$ of registered chiropractors in Australia in 2016. The majority of survey respondents were male (66.4\%) representing a gender distribution representative of registered chiropractors in Australia in 2016 (61.9\% male, $p=0.29$ ) (Table 1 ). The sample of 128 chiropractors had significantly different proportions in each age grouping compared to registered chiropractors in Australia $(p<0.001)$ with a greater proportion of respondents represented in older age groups.

The majority of the survey respondents obtained their chiropractic qualification in Australia $(89.1 \%, p<0.001)$ and qualified after $1990(p<0.001)$, with a mean of 21.7 (SD 11.3) years and range of 1 to 44 years in practice. Respondents were equally likely to be taught anatomy in Medicine, Science, Health Science, or another faculty $(p=0.153)$ (Table 1).

\section{Anatomy education: adequacy and relevance to clinical practice}

The majority of respondents either agreed or strongly agreed that the anatomy taught was adequate across all sub-disciplines for clinical practice (Table 2). The highest levels of agreement were in the sub-disciplines of gross anatomy, neuroanatomy, and histology. A similar pattern of response was observed regarding relevance of anatomical training to practice as a chiropractor (Table 2). The subdiscipline of embryology returned the highest proportion of negative response for both adequacy and relevance to practice with proportions of 15.0 and $18.9 \%$ respectively.

\section{Proportion of anatomy educators with a chiropractic qualification}

Regarding the qualifications of the anatomy educators of the respondents; only 39 out of 128 (30.5\%) were taught by academics with chiropractic qualifications, while 41 (32.0\%) were taught by academics with some clinical qualifications, such as medical or other allied health, and $41(32 \%)$ were taught by academics with no clinical qualifications. Seven (5.5\%) respondents were not aware of the qualifications of academic staff.

\section{Utility of different teaching tools}

Respondents had diverse perceptions of the usefulness of anatomy teaching tools used in their training (Table 3). The teaching tool rated most useful by respondents was cadaveric dissection followed by prosected cadavers, while the tool perceived as least useful was body painting surface anatomy. A large proportion of respondents were either unsure or had not used digital imaging $(44.5 \%)$ or interactive anatomy software (61.7\%) during their anatomy education.

\section{Discussion}

This survey is the first to investigate the perception of Australian registered chiropractors on the relevance and adequacy of their anatomy education to their clinical practice. The study found that the majority of respondents agreed that their professional degree training provided them with adequate anatomy knowledge for 
Table 1 Survey respondent's demographics compared to Australian registered chiropractors in 2016

\begin{tabular}{|c|c|c|}
\hline & Respondents n (\%) & Registered Chiropractors in $2016 \mathrm{n}(\%)$ \\
\hline \multicolumn{3}{|l|}{ Gender $^{a}$} \\
\hline Male & $85(66.4)$ & $3024(61.9)$ \\
\hline Female & $43(33.6)$ & $1864(38.1)$ \\
\hline Total & $128(100)$ & $4888(100)$ \\
\hline \multicolumn{3}{|l|}{ Age (years) } \\
\hline$<25$ & $2(1.6)$ & $105(2.1)$ \\
\hline $25-34$ & $15(11.7)$ & $1586(32.4)$ \\
\hline $35-44$ & $37(28.9)$ & $1422(29.1)$ \\
\hline $45-54$ & $34(26.6)$ & $941(19.3)$ \\
\hline $55-64$ & $34(26.6)$ & $570(11.7)$ \\
\hline$>65$ & $6(4.7)$ & $264(5.4)$ \\
\hline \multicolumn{3}{|c|}{ Country of qualification ${ }^{b}$} \\
\hline Australia & $114(89.1)$ & \\
\hline Elsewhere & $14(10.9)$ & \\
\hline \multicolumn{3}{|c|}{ Year of qualification ${ }^{c}$} \\
\hline$<1980$ & $15(11.7)$ & \\
\hline 1981-99 & $33(25.8)$ & \\
\hline$>1990$ & $80(62.5)$ & \\
\hline \multicolumn{3}{|c|}{ Anatomy home-faculty ${ }^{d}$} \\
\hline Medicine & $28(21.9)$ & \\
\hline Science & $38(29.7)$ & \\
\hline Health science & $33(25.8)$ & \\
\hline Other & $21(16.4)$ & \\
\hline Unsure & $8(6.3)$ & \\
\hline
\end{tabular}

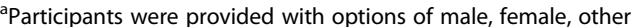

${ }^{\mathrm{b}}$ The majority of respondents qualified in Australia $(p<0.001$, Chi-square Test)

${ }^{C}$ Respondents were not evenly distributed across year of qualification $(p<0.001$, Chi-square Test)

${ }^{\mathrm{d}}$ Respondents were evenly distributed for anatomy home-faculty (excluding group: unsure) ( $p=0.153$, Chi-square Test)

Table 2 Proportion agreement that training in anatomy and knowledge in anatomy was adequate for practice

\begin{tabular}{llllll}
\hline $\begin{array}{l}\text { Anatomical } \\
\text { sciences sub- } \\
\text { discipline }\end{array}$ & $\begin{array}{l}\text { Strongly disagree or } \\
\text { disagree } \\
\mathrm{n}(\%)\end{array}$ & $\begin{array}{l}\text { Somewhat } \\
\text { disagree } \\
\mathrm{n}(\%)\end{array}$ & $\begin{array}{l}\text { Somewhat } \\
\text { agree } \\
\mathrm{n}(\%)\end{array}$ & $\begin{array}{l}\text { Agree or strongly } \\
\text { agree } \\
\mathrm{n}(\%)\end{array}$ & $\begin{array}{l}\text { Comparison across these } \\
\text { responses } \\
p \text { value }^{*}\end{array}$ \\
\hline $\begin{array}{l}\text { Training in } \\
\text { Gross } \\
\text { anatomy }\end{array}$ & $0(0)$ & $1(0.8)$ & $6(4.7)$ & $121(94.5)$ & $<0.001$ \\
Histology & $5(3.9)$ & $6(4.7)$ & $26(20.3)$ & $91(71.1)$ & $<0.001$ \\
$\begin{array}{l}\text { Neuroanatomy } \\
\text { Embryology }\end{array}$ & $9(0.8)$ & $0(0)$ & $13(10.2)$ & $114(89.1)$ & $<0.001$ \\
$\begin{array}{l}\text { Knowledge in } \\
\text { Gross }\end{array}$ & $0(0)$ & $10(7.9)$ & $29(22.8)$ & $79(62.2)$ & $<0.001$ \\
$\begin{array}{l}\text { anatomy } \\
\text { Histology }\end{array}$ & $9(7.1)$ & $1(0.8)$ & $1(0.8)$ & $126(98.4)$ & $<0.001$ \\
Neuroanatomy & $11(8.7)$ & $7(5.6)$ & $55(43.0)$ & $55(43.0)$ & $<0.001$ \\
Embryology & $11(8.7)$ & $13(10.2)$ & $38(29.9)$ & $65(51.2)$ & $<0.001$ \\
\hline
\end{tabular}

*Chi-squared test used to test if proportions are the same across $S D / D$, Somewhat $D$, Somewhat $A, A / S A$ responses 
Table 3 Respondents' perceptions of the utility of anatomy teaching tools and strategies

\begin{tabular}{|c|c|c|c|c|c|}
\hline Teaching resource & $\begin{array}{l}\text { Number } \\
\text { (n) }\end{array}$ & $\begin{array}{l}\text { Not helpful } \\
\mathrm{n}(\%)^{\mathrm{a}}\end{array}$ & $\begin{array}{l}\text { Slightly or moderately helpful } \\
\mathrm{n}(\%)^{\mathrm{a}}\end{array}$ & $\begin{array}{l}\text { Quite or extremely helpful } \\
\mathrm{n}(\%)^{\mathrm{a}}\end{array}$ & $\begin{array}{l}\text { Not used or unsure of utility } \\
n(\%)^{b}\end{array}$ \\
\hline Cadaveric dissection & 102 & $1(1.0)$ & $10(9.8)$ & $91(89.2)$ & $26(20.3)$ \\
\hline Prosected human cadavers & 110 & $0(0)$ & $12(10.9)$ & $98(89.1)$ & $15(11.7)$ \\
\hline Didactic lectures & 115 & $0(0)$ & $17(14.8)$ & $98(85.2)$ & $7(5.5)$ \\
\hline Medical imaging (e.g. X-ray) & 122 & $0(0)$ & $24(19.7)$ & $98(80.3)$ & $6(4.7)$ \\
\hline Interactive collaborative & 106 & $1(0.9)$ & $20(18.9)$ & $85(80.2)$ & $21(16.4)$ \\
\hline Reference text & 125 & $0(0)$ & $26(20.8)$ & $99(79.2)$ & $2(1.6)$ \\
\hline Digital imaging (atlas, 2-D, 3-D) & 70 & $0(0)$ & $17(24.3)$ & $53(75.7)$ & $57(44.5)$ \\
\hline Plastinated specimens & 98 & $1(1.0)$ & $30(30.6)$ & $67(68.4)$ & $28(21.9)$ \\
\hline Models & 122 & $1(0.8)$ & $40(32.8)$ & $81(66.4)$ & $5(3.9)$ \\
\hline Interactive anatomy software ${ }^{a}$ & 45 & $0(0)$ & $15(33.3)$ & $30(66.7)$ & $79(61.7)$ \\
\hline Laboratory manuals & 111 & $1(0.9)$ & $41(36.9)$ & $69(62.2)$ & $16(12.5)$ \\
\hline Body painting surface anatomy & 55 & $2(3.6)$ & $26(47.3)$ & $27(49.1)$ & $72(56.3)$ \\
\hline
\end{tabular}

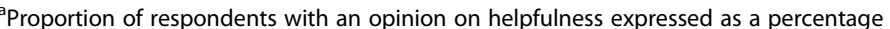

bProportion of respondents who answered question who had either not used the utility or were unsure if they had used it expressed as a percentage

clinical practice. Respondents perceived all of the four sub-disciplines of gross anatomy, neurology, histology, and embryology to be relevant to their daily clinical practice. The highest levels of agreement for both adequacy of training and relevance for clinical practice were in the sub-disciplines of gross anatomy, neuroanatomy, and histology. The respondents rated the most useful teaching resources to be cadaveric dissection followed by access to prosected cadavers. One possible reason for the general homogeneity in responses is that most of the respondents graduated from Australian training programs $(89 \%)$ and that these educational programs are not significantly dissimilar [8].

The findings of this study are similar to the opinions of medical doctors and other allied health professionals who also considered anatomy to be highly relevant to their daily clinical practice [16, 17, 22, 23]. Osteopaths very similarly rated gross anatomy and neurology as the most relevant subdisciplines to their clinical practice [24]. The similarity of findings is possibly due to interdisciplinary overlap [25].

The finding that the respondents perceived their training to be relatively less adequate in the sub-disciplines of embryology and histology could be linked to their perception of the same subdisciplines as least relevant to their clinical practice. This may be reflective of the situation that embryology and histology were not always taught in all Australian chiropractic programs and if taught, possibly not directly linked to professional practice [8]. The rationale for the exclusion of these subdisciplines in chiropractic curriculum was beyond the scope of this survey however, it does raise questions regarding the relevance and core content of the disciplines that are considered a requirement for chiropractic clinical practice. There is no literature available in this area. The consequences of not including embryology and histology in chiropractic training may potentially impact professional practice, particularly in relation to the clinical understanding of a wide range of musculoskeletal pathologies. This has the potential to negatively impact the profession's role in patient education and professional status. Furthermore, the knowledge gap could adversely impact future interdisciplinary collaboration for the chiropractic profession and threaten its position at the nexus between mainstream and alternative medicine [26].

\section{Range of teaching resources}

Anatomy is a discipline that utilizes a wide range of teaching tools and strategies. The survey confirmed that chiropractors were exposed to a suite of teaching tools and strategies rather than a single resource (Table 3), similar to that utilized in medical anatomy teaching [27]. The use of a varied range of teaching tools indicates that anatomy was taught in an enriched format including formal, informal, didactic (traditional) and student-directed pedagogies. It also confirms that anatomy teachers were cognizant of the usefulness of each of the tools and implemented these in ways that enabled learning amongst the diverse student cohorts over time [28, 29].

The majority of respondents in this survey (62.5\%) were taught anatomy by at least one anatomy academic with a clinical qualification, with one-third of respondents indicating that all of the staff involved in their anatomy education held chiropractic qualifications. This is not an accreditation criterion stipulated by the Council on Chiropractic Education Australasia (CCEA) but remains at the discretion of the teaching program [9]. The response is suggestive of the value that is placed on 
clinicians' input (e.g. through demonstration of clinical relevance) into the teaching programs [30] and may reflect both the availability of clinicians who can teach anatomy and the acknowledgement of the importance of clinical competency by the course coordinators. The benefit of correlating anatomical content to clinical relevance also assists to mentor students towards possible future academic career paths, in addition to ensuring that anatomy is taught and adapted to 'real-world' clinical scenarios [31, 32].

Irrespective of whether chiropractic anatomists deliver the anatomy content, anatomy is often further integrated with content delivered subsequently within chiropractic education programs in a spiral program design. For some of the later content such as chiropractic manipulative technique, anatomy is both foundational and imperatively provides an opportunity to reinforce clinically relevant anatomy [33]. This symbiotic relationship is further enhanced when relevant chiropractic content is taught in parallel with anatomy, thus aligning anatomical theory with clinical decision making [30,34, 35]. This is equally as useful in the undergraduate years when the students are learning anatomy for the first time as it is in the later years of their programs.

\section{The utility of teaching resources}

The survey respondents highly regarded cadaveric learning as a teaching tool with the majority of respondents reporting access to human cadavers either via dissection $(80 \%)$ or prosected specimens $(86 \%)$ during their training, and they were perceived as the most helpful of all the teaching tools. This is in line with the argument made by many anatomy and medical educators that cadavers, whether via dissection or examination of prosected body parts, present an invaluable educational resource [28]. Access to human cadavers as a teaching tool provides an opportunity for students to develop three-dimensional perspectives of the human body and to appreciate clinically relevant anatomical variations [36-38]. This enhanced spatial awareness may assist with integrating anatomy knowledge to the application of clinical techniques [39]. The chiropractic profession's predilection towards a hands-on approach may also be a reason why the respondents perceived cadaveric dissection and use of prosected specimens as the most helpful of the anatomy teaching tools [40]. The opportunity to learn from the experience of interacting with human cadavers is important to health education. For example, access to human cadavers serves to introduce students to the concept of death and instils respect and empathy from very early in their professional training [41].

In addition to the hands-on exposure to cadavers, the majority of respondents also agreed that the use of didactic lectures was a useful learning tool. This may be attributed to the efficiency by which didactic lectures are able to deliver a large volume of information and highlight the most relevant aspects of a body of knowledge [42]. Student perceptions of conventional didactic lectures are thought to be dependent on the lecturer delivering the material, which may have influenced responses for those who reported exposure to educators with clinical experience [43], who could demonstrate use of content knowledge in a clinical setting.

The use of radiological imaging was also perceived by the respondents to be valuable. The use of radiological images as a teaching resource serves to enhance students' structural competency and provides a link between understanding the 2D representation to the anatomy in situ [44]. This finding may reflect that some chiropractors in Australia use spinal $\mathrm{x}$-rays for assessing spine and intersegmental alignment to support clinical decision making. Chiropractors are eligible for licensure to use and own $\mathrm{x}$ ray machines in addition to having referral rights to medical radiologists for spinal images [45].

In contrast, the teaching tools least utilized by the respondents included the use of interactive software, digital imaging 2D and 3D atlases along with the use of surface anatomy body painting, possibly reflective of the age of the respondents. As most of the respondents are of a relatively older generation, they may not have found the digital resources as useful as the current generation of learners, the so-called "digital natives" [46]. It should also be noted that these digital resources might not have been available in a sophisticated, easy to use form, as they are today, and therefore not deemed useful as compared to traditional anatomy teaching resources.

\section{Study limitations}

The small sample size may not capture the full range of opinions and perceptions possible, which may limit the generalizability of the study findings. This study should be interpreted within the context of sample limitations and it should be noted that certain responses are based on respondents accurately remembering details, for example, the qualifications of their educators. The study was further limited in that it was not possible to determine the core content that participants received in each sub-discipline. This was beyond the scope of this survey. It is unclear if the level of exposure to certain teaching resources during training, has influenced the survey results. Most of the respondents were educated in Australia, therefore the findings may not be generalizable to other countries.

\section{Directions for future research}

This study identified heterogeneity in the perceived relevance across anatomy subdisciplines, along with a wide variation in the utilization of teaching resources. It is unclear if the observed variation may reflect a lack of 
detailed guidance from the accrediting body on recommended course structure, or some other mechanism. Future studies may explore the drivers of individual program content, staffing and modes of delivery for anatomy education. In addition, it is unclear if the selfreported high-level agreement that training in anatomy was adequate, aligns with objective assessment of anatomical knowledge retained by chiropractors in the clinical setting. Future studies that seek to measure the anatomical knowledge of chiropractors should be conducted.

\section{Conclusion}

Chiropractic is a primary contact clinical discipline relying on the application of anatomy knowledge for sound diagnosis and management of musculoskeletal health conditions. Most respondents agreed that training in gross anatomy and neuroanatomy was adequate and highly relevant to their practice. In contrast, whilst approximately two-thirds of respondents agreed that training in histology and embryology was adequate, they rated these anatomy subdisciplines as less relevant to clinical practice. The majority of respondents indicated that they were taught anatomy by clinically qualified staff, with access to a varied suite of teaching tools, of which cadaveric dissection and use of prosected specimens were perceived as the most beneficial to their clinical practice.

This study highlights the importance of including current clinicians' opinions when reviewing anatomy courses in chiropractic degree programs. The results of this study may inform future delivery of anatomical content in academic programs for the chiropractic profession.

\section{Abbreviations}

CCEA: Council on Chiropractic Education Australasia

\section{Acknowledgements}

Not applicable.

\section{Authors' contributions}

RG- made substantial contribution to the design of the survey, the interpretation and analysis of data, the writing of the manuscript. GS - made substantial contribution to the design of the survey, the interpretation of data and edits to final paper. TP - made substantial contribution to the interpretation and analysis of data and edits to final paper. NP - made substantial contribution to the design of the survey, the interpretation of data and edits to final paper. The author(s) read and approved the final manuscript.

\section{Funding}

No funding was sought or provided for this study.

\section{Availability of data and materials}

The datasets analysed during the current study are held in the Research Data Management at UNSW repository: D0237583 Survey of health professionals' perceptions of the appropriateness of the anatomy learnt during their professional training for practice and available on request.

\section{Ethics approval and consent to participate}

Ethical approval was obtained from the Human Research Ethics Committee of UNSW, Sydney (HC17058)
Consent for publication

Not applicable.

\section{Competing interests}

The authors declare that they have no competing interests.

\section{Author details}

${ }^{1}$ Department of Anatomy, School of Medical Sciences, Faculty of Medicine, The University of New South Wales, Sydney, New South Wales, Australia. ${ }^{2}$ Department of Chiropractic, Faculty of Science and Engineering, Macquarie University, Macquarie Park, Australia. ${ }^{3}$ Department of Mathematics and Statistics, Faculty of Science and Engineering, Macquarie University, Sydney, New South Wales, Australia.

Received: 22 February 2020 Accepted: 4 June 2020

Published online: 16 July 2020

\section{References}

1. WFC. World Federation of Chiropractic. Definitions of Chiropractic. World Federation of Chiropractic. 2019.World Federation of Chiropractic, Toronto, Ontario, Canada. Available from:https://www.wfc.org/website/index. php?option=com_content\&view=article\&id=90\&ltemid=110\&lang=en.

2. Cramer G, Budgell B, Henderson C, Khalsa P, Pickar J. Basic science research related to chiropractic spinal adjusting: the state of the art and recommendations revisited. J Manip Physiol Ther. 2006:29(9):726-61.

3. Australian Institute of Health and Welfare 2019. Musculoskeletal conditions and comorbidity in Australia. Arthritis series no 25 Cat no PHY 241. Canberra: AlHW; 2019.

4. Xue CC, Zhang AL, Lin V, Myers R, Polus B, Story DF. Acupuncture, chiropractic and osteopathy use in Australia: a national population survey. BMC Public Health. 2008;8(1):105.

5. Gouveia LO, Castanho P, Ferreira JJ. Safety of chiropractic interventions: a systematic review. Spine. 2009;34(11):E405-E13.

6. Ebrall P. Takeyachi K. International equivalency for first-professional programs of chiropractic education. Chiropr J Aust. 2004;34(3):103.

7. Bolton SP. Chiropractic education in Australia: a short history of its emergence and development. Chiropr J Aust. 2010;40(2):88.

8. Giuriato R, Štrkalj G, Meyer AJ, Pather N. Anatomical sciences in chiropractic education: a survey of chiropractic programs in Australia. Anat Sci Educ. 2019:47:37-47.

9. Council on Chiropractic Education Australasia (CCEA) Ltd. Accreditation standards for chiropractic programs competency standards for graduating chiropractors. 2017. Available from:http://www.ccea.com.au/files/1015/045 0/1916/CCEA_Accreditation_and_Competency_Standards_2017.10.

10. Council on Chiropractic Education Australasia (CCEA) Ltd. Educational standards for first professional award programs in chiropractic 2009, vol. 15; 2009. Available from:https://www.ccea.com.au/files/1015/0450/1916/CCEA Accredutation_and_Competenc_Standards_2017.pdr74/CCEA_Educational_ Standards_- First_Professional___December_2009.

11. Štrkalj GBR, Štrkalj M, Sierpina VS, Kreitzer MJ. Teaching anatomy to chiropractic students: experiences from Macquarie University, Sydney. Explore - NY. 2012;8(2):141-4

12. Kember $D$, Ho A, Hong C. The importance of establishing relevance in motivating student learning. Act Learn High Educ. 2008:9(3):249-63.

13. Štrkalj G, Hulme A, El-Haddad J, Luo K, Crafford DRM. Students' perceptions and usage of short anatomy videos: a preliminary study. Int J Morphol. 2018;36(2):493-9.

14. Bergman EM, De Bruin AB, Herrler A, Verheijen IW, Scherpbier AJ, Van Der Vleuten CP. Students' perceptions of anatomy across the undergraduate problem-based learning medical curriculum: a phenomenographical study. BMC Med Educ. 2013;13(1):152.

15. Schneider M, Murphy D, Hartvigsen J. Spine care as a framework for the chiropractic identity. J Chiropr Humanit. 2016;23(1):14-21.

16. Arráez-Aybar L-A, Sánchez-Montesinos I, Mirapeix R-M, Mompeo-Corredera B, Sañudo-Tejero J-R. Relevance of human anatomy in daily clinical practice. Ann Anat. 2010;192(6):341-8.

17. Sbayeh A, Choo MAQ, Quane KA, Finucane P, McGrath D, O'flynn S, et al. Relevance of anatomy to medical education and clinical practice: perspectives of medical students, clinicians, and educators. Perspect Med Educ. 2016;5(6):338-46. 
18. Gelder C, Paterson-Brown S. The role of anatomy in surgical training and the use of cadaveric training courses. Ann R Coll Surg Engl. 2015;97(3):123-6.

19. Sullivan $G M$, Artino AR Jr. Analyzing and interpreting data from Likert-type scales. J.Grad.Med.Educ. 2013:5(4):541-2.

20. Australia Chiropractic Board of Australia. 2015/16 annual report summary 2016. Available from: https://www.ahpra/gov.au/annualreport/2016/html/ board-summaries/chiroba-summary.html.

21. Walker BF, Stomski NJ, Hebert JJ, French SD. A survey of Australian chiropractors' attitudes and beliefs about evidence-based practice and their use of research literature and clinical practice guidelines. Chiropr Man Ther. 2013;21(1):44.

22. Rowland S, Ahmed K, Davies DC, Ashrafian H, Patel V, Darzi A, et al. Assessment of anatomical knowledge for clinical practice: perceptions of clinicians and students. Surg Radiol Anat. 2011;33(3):263-9.

23. Cho MJ, Hwang Y-I. Students' perception of anatomy education at a Korean medical college with respect to time and contents. Anat Cell Biol. 2013; 46(2):157-62.

24. Blaich R, Pather N, Luo K, Štrkalj G. Australian osteopathic practitioners' perceptions of the clinical relevance of anatomy. Int J Morphol. 2019;37(1):319-23.

25. Nancarrow SA, Borthwick AM. Dynamic professional boundaries in the healthcare workforce. Sociol Health IIIn. 2005;27(7):897-919.

26. Meeker WC, Haldeman S. Chiropractic: a profession at the crossroads of mainstream and alternative medicine. Ann Intern Med. 2002;136(3):216-27.

27. Estai $\mathrm{M}$, Bunt $\mathrm{S}$. Best teaching practices in anatomy education: a critical review. Ann Anat. 2016;208:151-7.

28. Pather N. Teaching anatomy: prosections and dissections. In: Chan LK, Pawlina W, editors. Teaching anatomy: a practical guide. Cham: Springer International Publishing; 2015. p. 213-21.

29. Merriam SB, Baumgartner LM. Learning in adulthood: a comprehensive guide. Hoboken: Wiley; 2020. p. 5-26.

30. Smith CF, Mathias HS. What impact does anatomy education have on clinical practice? Clin Anat. 2011;24(1):113-9.

31. Mercer SR, Rivett DA. Clinical anatomy serving manual therapy. Man Ther. 2004;9(2):59.

32. Leveritt $\mathrm{S}$, McKnight $\mathrm{G}$, Edwards $\mathrm{K}$, Pratten M, Merrick D. What anatomy is clinically useful and when should we be teaching it? Anat Sci Educ. 2016;9:468-75.

33. Harden RM. What is a spiral curriculum? Med Teach. 1999;21(2):141-3.

34. McHanwell S, Smith C. Teaching anatomy to students in professions allied to medicine. J Anat. 2012;221:73-96.

35. McBride JM, Drake RL. National survey on anatomical sciences in medical education. Anat Sci Educ. 2018;11(1):7-14.

36. Ramsey-Stewart G, Burgess AW, Hill DA. Back to the future: teaching anatomy by whole-body dissection. Med J Aust. 2010;193(11):668.

37. Older J. Anatomy: a must for teaching the next generation. J Surg. 2004 2(2):79-90.

38. Louw G, Eizenberg N, Carmichael SW. The place of anatomy in medical education: AMEE 41. Med Teach. 2009:31(5):373-86.

39. Langlois J, Bellemare C, Toulouse J, Wells GA. Spatial abilities and anatomy knowledge assessment: a systematic review. Anat Sci Educ. 2017;10(3):235-41.

40. Peeler J, Bergen H, Bulow A. Musculoskeletal anatomy education: evaluating the influence of different teaching and learning activities on medical students perception and academic performance. Ann Anat. 2018;219:44-50.

41. Flack NA, Nicholson HD. What do medical students learn from dissection? Anat Sci Educ. 2017;11(4):325-35.

42. Charlton BG. Lectures are such an effective teaching method because they exploit evolved human psychology to improve learning. Med Hypotheses. 2006;67:1261-5.

43. AlHaqwi Al, Taha WS. Promoting excellence in teaching and learning in clinical education. J Taibah Univ Sci. 2015:10(1):97-101.

44. Phillips AW, Smith SG, Straus CM. The role of radiology in preclinical anatomy: a critical review of the past, present, and future. Acad Radiol. 2013;20(3):297-304.

45. Jenkins HJ, Downie AS, Moore CS, French SD. Current evidence for spinal Xray use in the chiropractic profession: a narrative review. Chir Manual Ther 2018:26(1):48.

46. Prensky MR. From digital natives to digital wisdom: hopeful essays for 21st century learning. Thousand Oaks: Corwin Press; 2012

\section{Publisher's Note}

Springer Nature remains neutral with regard to jurisdictional claims in published maps and institutional affiliations.

\section{Ready to submit your research? Choose BMC and benefit from:}

- fast, convenient online submission

- thorough peer review by experienced researchers in your field

- rapid publication on acceptance

- support for research data, including large and complex data types

- gold Open Access which fosters wider collaboration and increased citations

- maximum visibility for your research: over $100 \mathrm{M}$ website views per year

At $\mathrm{BMC}$, research is always in progress.

Learn more biomedcentral.com/submissions 